Review

\title{
Metabolic Interactions of Purine Derivatives with Human ABC Transporter ABCG2: Genetic Testing to Assess Gout Risk
}

\author{
Toshihisa Ishikawa ${ }^{1, *}$, Wanping $\mathrm{Aw}^{2}$ and Kiyoko Kaneko ${ }^{3}$
}

1 RIKEN Center for Life Science Technologies, 1-7-22 Suehiro-cho, Tsurumi-ku, Yokohama 230-1145, Japan

2 Graduate School of Biomedical Science, Tokyo Medical Dental University, 1-5-45 Yushima, Bunkyo-ku, Tokyo 113-8510, Japan

3 Laboratory of Biomedical and Analytical Sciences, Faculty of Pharma Sciences, Teikyo University, 2-11-1 Kaga, Itabashi-ku, Tokyo 173-8605, Japan

* Author to whom correspondence should be addressed; E-Mail: toshi-i@gsc.riken.jp or toshihisa.ishikawa.r@gmail.com; Tel.: +81-45-503-9222; Fax: +81-45-503-9216.

Received: 30 September 2013; in revised form: 22 October 2013 / Accepted: 27 October 2013 / Published: 4 November 2013

\begin{abstract}
In mammals, excess purine nucleosides are removed from the body by breakdown in the liver and excretion from the kidneys. Uric acid is the end product of purine metabolism in humans. Two-thirds of uric acid in the human body is normally excreted through the kidney, whereas one-third undergoes uricolysis (decomposition of uric acid) in the gut. Elevated serum uric acid levels result in gout and could be a risk factor for cardiovascular disease and diabetes. Recent studies have shown that human ATP-binding cassette transporter ABCG2 plays a role of renal excretion of uric acid. Two non-synonymous single nucleotide polymorphisms (SNPs), i.e., 421C $>\mathrm{A}$ (major) and $376 \mathrm{C}>\mathrm{T}$ (minor), in the $A B C G 2$ gene result in impaired transport activity, owing to ubiquitination-mediated proteosomal degradation and truncation of ABCG2, respectively. These genetic polymorphisms are associated with hyperuricemia and gout. Allele frequencies of those SNPs are significantly higher in Asian populations than they are in African and Caucasian populations. A rapid and isothermal genotyping method has been developed to detect the SNP 421C $>$ A, where one drop of peripheral blood is sufficient for the detection. Development of simple genotyping methods would serve to improve prevention and early therapeutic intervention for high-risk individuals in personalized healthcare.
\end{abstract}

Keywords: ABC transporter; ABCG2; gout; hyperuricemia; kidney; SNP; uric acid 


\section{Introduction}

In our body, nutrients and xenobiotics are not only enzymatically metabolized, but also transported by various transporters including members of the solute carrier (SLC) superfamily and some ATP-dependent efflux pumps of the ATP-binding cassette (ABC) superfamily [1]. Transporter proteins mediating the uptake and efflux of metabolites into and out of cells are key determinants of the in vivo distribution and elimination of a variety of endogenous substances and xenobiotics. The human ATP-binding cassette $(\mathrm{ABC})$ protein family involves a total 48 different genes, and they are classified into seven sub-families (from A to G) [2]. While ABCG2 was originally identified as a multi-drug efflux pump in drug-resistant breast cancer MCF-7/AdrVp cells [3], recent studies have shown that ABCG2 is an important human uric acid transporter in the kidney [4]. Genetic polymorphisms (421C $>\mathrm{A}$ and $376 \mathrm{C}>\mathrm{T})$ in the $A B C G 2$ gene have been identified to cause hyperuricemia and gout [4,5]. In this review article, we provide an overview on the physiological role of human ABC transporter ABCG2 in purine metabolism and propose genotyping-based "personalized healthcare" to assess gout risk.

\section{Purine Metabolism}

Purines are components of nucleosides, the building blocks of DNA and RNA. Purine nucleosides, i.e., adenosine and guanine, are used in the creation of other metabolically important factors as well, such as ATP, GTP, cyclic AMP, S-adenosylmethionine, nicotinamide adenine dinucleotide (NADH), and nicotinamide adenine dinucleotide phosphate (NADPH). The family of purine and its derivatives includes adenine, guanine, isoguanine, hypoxanthine, xanthine, theobromine, caffeine, and uric acid (Figure 1).

Figure 1. Chemical structures of purine and its derivatives, i.e., adenine, guanine, hypoxanthine, xantine, theobromine, caffeine, uric acid, and isoguanine.

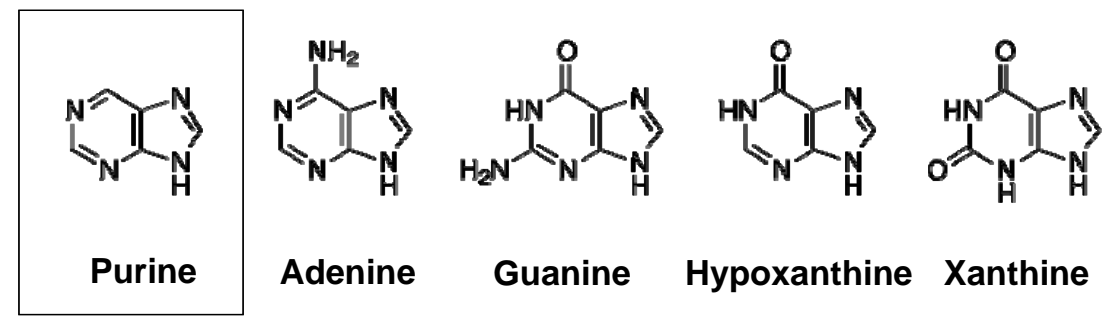

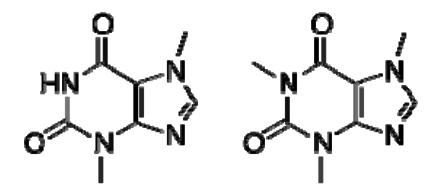

Theobromine Caffeine<smiles>O=c1[nH]c2[nH]c(=O)[nH]c2[nH]1</smiles>

Uric acid<smiles>Nc1[nH]c(=O)nc2[nH]cnc12</smiles>

Isoguanine

Given the importance of purine-containing molecules for survival, vertebrates, including humans, have developed robust systems for synthesizing sufficient purine nucleosides for their metabolism using readily available materials (such as glucose, glycine, and glutamine), as well as recycling purine nucleosides from throughout the body or from the diet. 
In mammals, excess purine nucleosides are removed from the body by breakdown in the liver and excretion from the kidneys. For most mammals, the purines are first converted into the intermediate uric acid, which is then metabolized by the enzyme uricase into the compound allantoin. Allantoin is a very soluble compound that can easily travel through the bloodstream, become filtered by the kidneys, and be excreted from the body. In contrast to other mammals, humans and primates lack a functional uricase enzyme, and can only break purines down into uric acid. Figure 2 depicts the metabolic pathways of purine catabolism and uric acid formation. The metabolic pathways consist of multiple steps of reactions catalyzed by various enzymes, such as AMP deaminase, adenosine deaminase, 5'-nucleotidase, purine nucleoside phosphorylase, guanine deaminase, and xanthine oxidase. In humans, uric acid is the final product of purine metabolism.

Figure 2. Metabolic pathways of uric acid formation from nucleotide monophosphates. AMP, adenosine monophosphate; IMP, inosine monophosphate; XMP, xanthine monophosphate, GMP, guanine monophosphate.

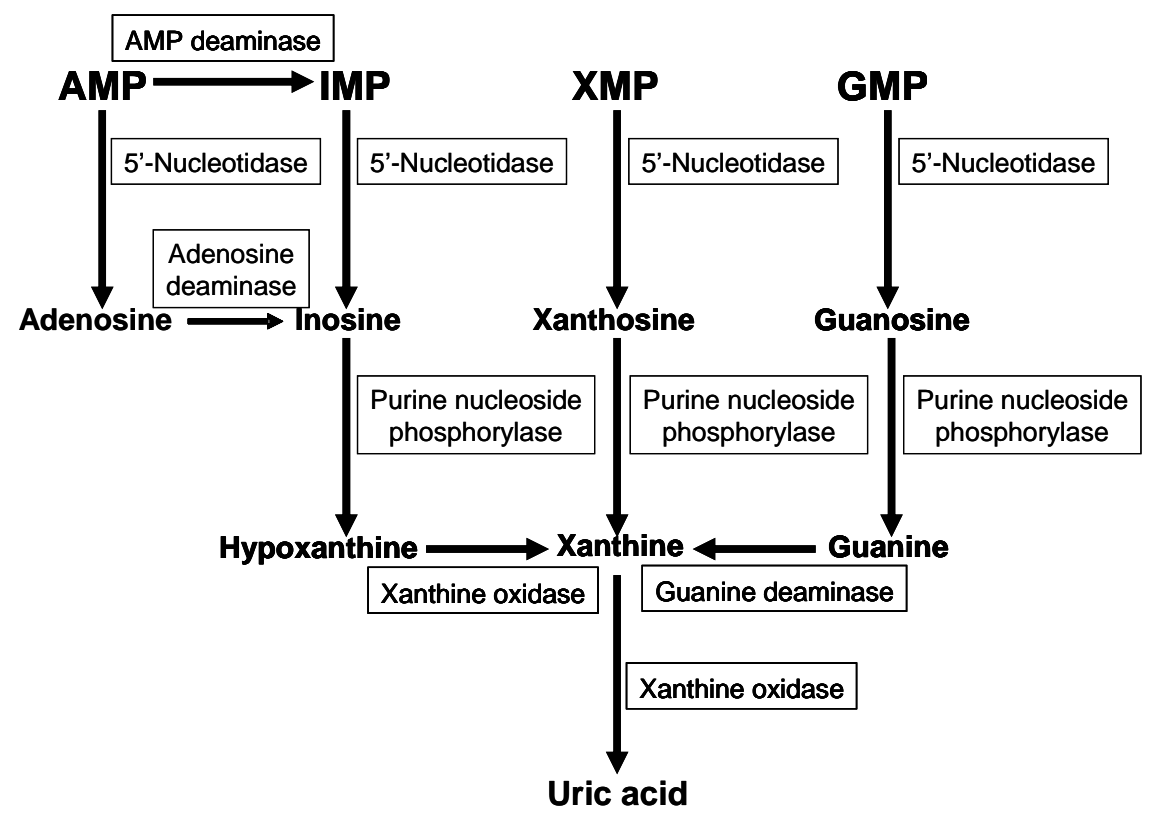

\section{Renal Excretion of Uric Acid}

The levels of uric acid in the blood depend on two factors. The first is the rate of uric acid synthesis in the liver. Since uric acid results from purine degradation, its levels are influenced by both the amount of purines synthesized in the body, as well as the amounts of purines absorbed from the diet [6]. The second determinant of blood uric acid levels is the rate of uric acid excretion from the kidneys. Excretion has the greatest effect on blood uric acid levels, with about $90 \%$ of hyperuricemia cases attributed to impaired renal excretion [7].

It is suggested that hyperuricemia increases the risk of not only gout, but also other diseases as well, including hypertension, kidney disease, and metabolic syndrome [8]. Even during the asymptomatic periods between gout attacks, the body is exposed to periods of low-grade, chronic inflammation. The propensity for excessive blood uric acid and gout can also be increased by other disease states [9]. 
It is important, therefore, to prevent the onset of gout. Early therapeutic intervention is needed for high-risk individuals.

Impaired excretion is most often due to abnormalities in uric acid transporters expressed in the kidney $[4,10,11]$. Uric acid transporters control the movement of uric acid through renal proximal tubules, as shown in Figure 3. The physiological relevance of uric acid transporters in humans is established by genetic variation causing hyper-/hypo-uricemia and gout. SLC22A12 (URAT1) and SLC2A9 (URATv1/GLUT9) are major players in the re-absorption of uric acid into blood [12-17], whereas SLC22A6 (OAT1), SLC22A8 (OAT3), SLC17A3 (NPT4), ABCC4 (MRP4), and ABCG2 (BCRP) are involved in the renal secretion of uric acid into urine [4,18-21].

Figure 3. Schematic illustration of renal re-absorption and excretion of uric acid. Uric acid filtrated from the renal glomerular body is first re-absorbed by human renal proximal tubule cells. Thereafter, uric acid is eliminated, in part, from the blood circulation to urine by renal transporters. Arrows in the figure indicate the direction of transport of uric acid. Dotted and solid lines indicate re-absorption and secretion, respectively.

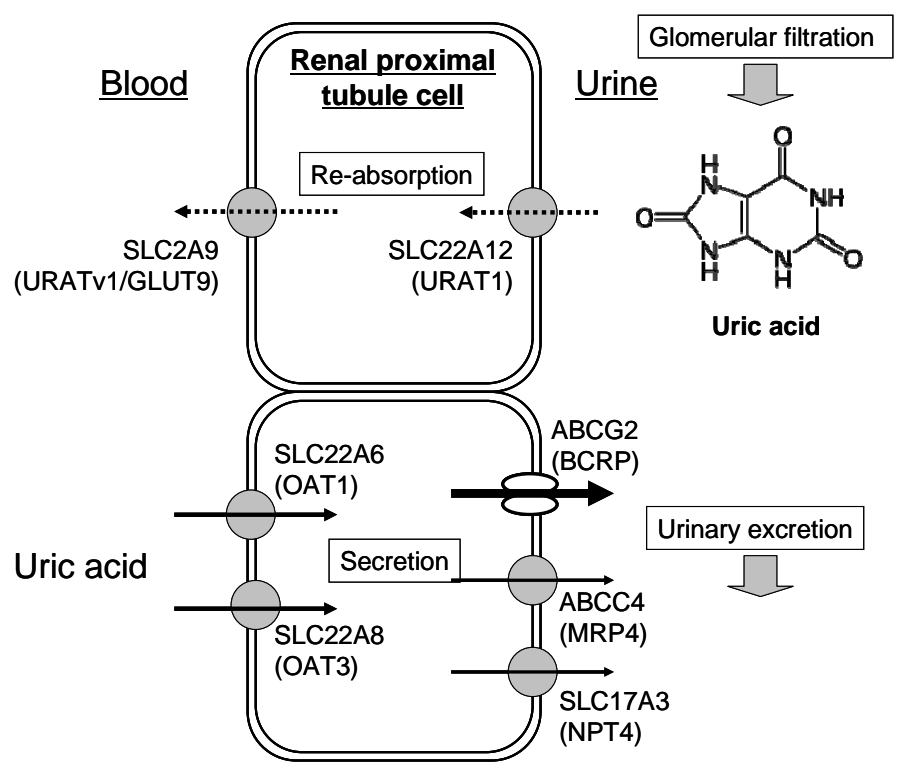

\section{Cause of Gout and Therapeutics}

Gout is one of the oldest known and most common forms of arthritis; it is a crystal deposition disease in which crystals of monosodium urate form in joints and other tissues [22,23]. Gout usually involves sudden attacks of severe pain, often in the joint at the base of the big toe and frequently in the wee hours of the morning, when body temperature is lowest. Gout attacks cause a characteristic painful inflammation of one or more joints of the extremities, or nodules in soft tissues called tophi. An acute attack of gout, although brief and usually subsiding spontaneously, can be temporarily debilitating, and predisposes an individual to subsequent attacks.

For therapeutic intervention of gout, several drugs were developed and are widely used. Xanthine oxidase inhibitors, for example, reduce the activity of xanthine oxidase, the final step in uric acid synthesis. This has the effect of lowering uric acid production. Allopurinol (Zyloprim) has a long history of usage as a xanthine oxidase inhibitor; recently febuxostat (Uloric) has been approved for 
treatment of hyperuricemia in the US. Febuxostat exhibits greater uric acid-lowering effects than allopurinol, although the incidence of gout flares is similar between the two drugs [24]. Uricosuric drugs are also often used to reduce uric acid level in the systemic blood circulation, primarily by reducing the re-absorption of uric acid from the kidneys back into the blood. Probenecid (Benemid) and sulfinpyrazone (Anturane) are two examples. These drugs, however, tend to increase urinary uric acid levels, which can cause kidney stones. Recently, the outside and inside of the kidney stones were measured non-destructively with a micro area X-ray diffractometer [25]. Proteins, such as uromodulin and albumin, are often detected in stones regardless of crystal components, where uromodulin is the most abundant urinary glycoprotein. Furthermore, immunoglobin $G$ fragments were also detected in uric acid stones [25]. In some persons with loss-of-function mutations of URAT1, uricosurics such as benzbromarone and losartan had no effect, suggesting these drugs act on URAT1 in vivo [26].

\section{Genetic Analysis of Gout Risk}

Recently, large meta-analyses of GWAS have revealed that SNPs in the SLC2A9 (GLUT9) and $A B C G 2$ genes are strongly associated with the phenotype of gout [27-29]. Since serum levels of uric acid are highly heritable, the involvement of genetic factors in gout was previously speculated. Several laboratories have independently found that the SNP 421C $>$ A in the ABCG2 gene (Figure 4) is one of the major genetic factors for elevated serum uric acid levels and the increased risk of gout $[4,5,30]$.

Figure 4. Schematic illustration of human ABCG2 and its non-synonymous polymorphisms. The ABCG2 protein expressed in the plasma membrane is a homodimer linked via a cysteinyl disulfide bond. The cysteine residue corresponding to Cys603 of human ABCG2 is involved in the homodimer formation, whereas Cys592 and Cys608 form an intra-molecular disulfide bond that is important for $N$-linked glycan formation at Asn596. The SNP $421 \mathrm{C}>\mathrm{A}$ is a non-synonymous polymorphism that leads to amino acid substitution; Gln to Lys (Q141K) in the intracellular loop containing an ATP-binding cassette (ABC).

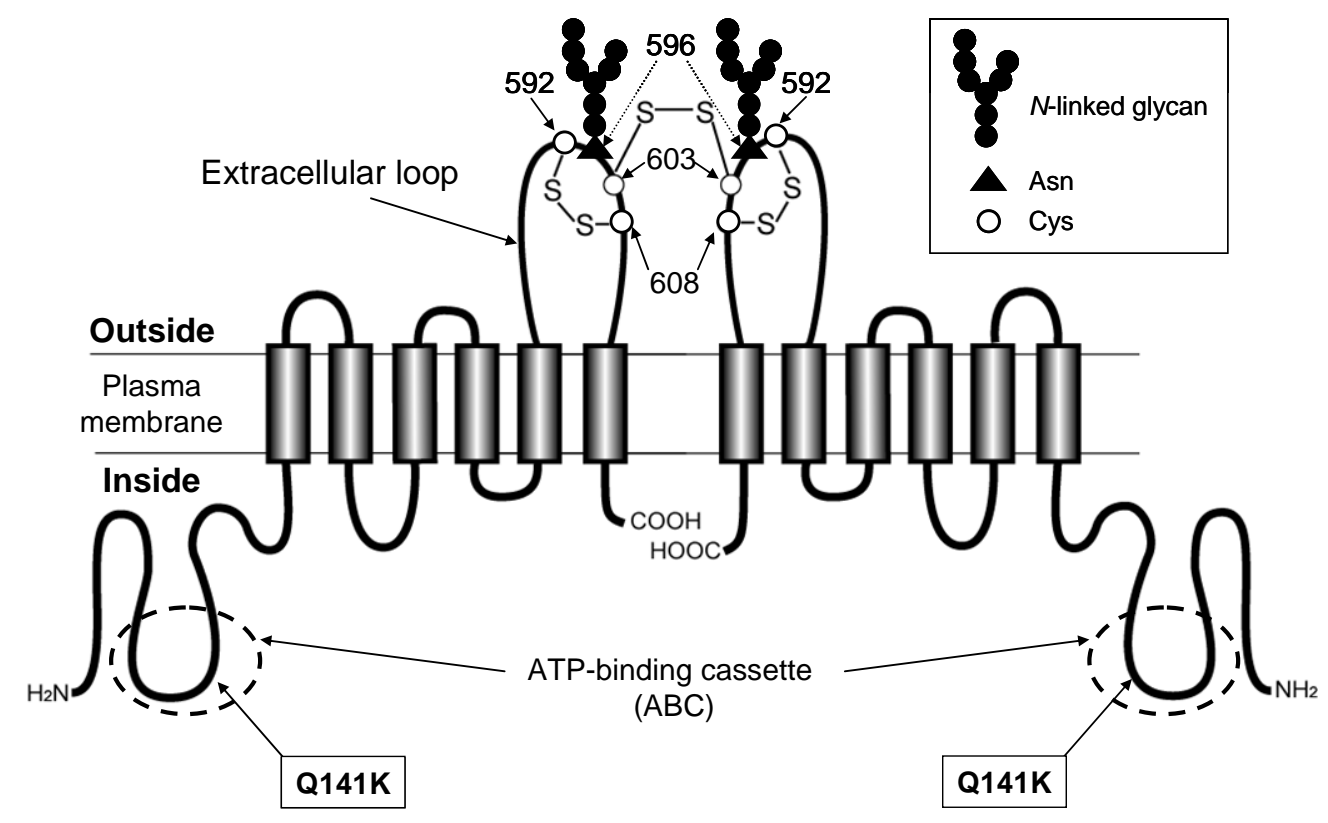


ABCG2 expressed on the apical side of the proximal tubular cells in human kidney plays a pivotal role in renal excretion of serum uric acid. Introduction of the mutation Q141K encoded by the common SNP (rs2231142) by site-directed mutagenesis resulted in 53\% reduced urate transport rates compared to wild-type ABCG2 $(p<0.001)$. The expression levels of the Q141K variant are reduced by ubiquitin-mediated proteasomal degradation [31-34] (Figure 5). Thus, renal excretion of serum uric acid via ABCG2 is impaired in persons who are carrying the 421A allele (Q141K variant). As a consequence, serum uric acid levels are elevated, which enhances the risk of gout.

Figure 5. Effect of the SNP variant $(\mathrm{Q} 141 \mathrm{~K})$ on the protein expression level and degradation of ABCG2. (A) The ABCG2 wild type (WT) protein has glutamine residue at amino acid position 141. To assess the effect of Q141K variant on the protein expression level, Flp-In-293 cells expressing WT and the Q141K variant were incubated in the absence or presence of MG132 $(2 \mu \mathrm{M})$ for $24 \mathrm{~h}$. ABCG2 WT and Q141 variant proteins were analyzed by immunoblotting with the ABCG2-specific monoclonal antibody (BXP-21) after PNGase F treatment. The glyceraldehyde-3-phosphate dehydrogenase (GAPDH) protein level was analyzed by GAPDH-specific antibody. The signal intensity ratio (ABCG2/GAPDH) was normalized to the control level. Data are expressed as means \pm S.D. in triplicate experiments [33]. (B) Correctly processed ABCG2 WT protein is destined to reach the plasma membrane and is then degraded by the endosome-lysosome pathway after remaining in the plasma membrane domain for a certain period. In contrast, the ABCG2 $\mathrm{Q} 141 \mathrm{~K}$ variant protein is recognized as a misfolded form and then undergoes ubiquitination-mediated proteasomal degradation. Bafilomycin $\mathrm{A}_{1}$ (BMA) and MG132 inhibit lysosomal and proteasomal degradation, respectively.
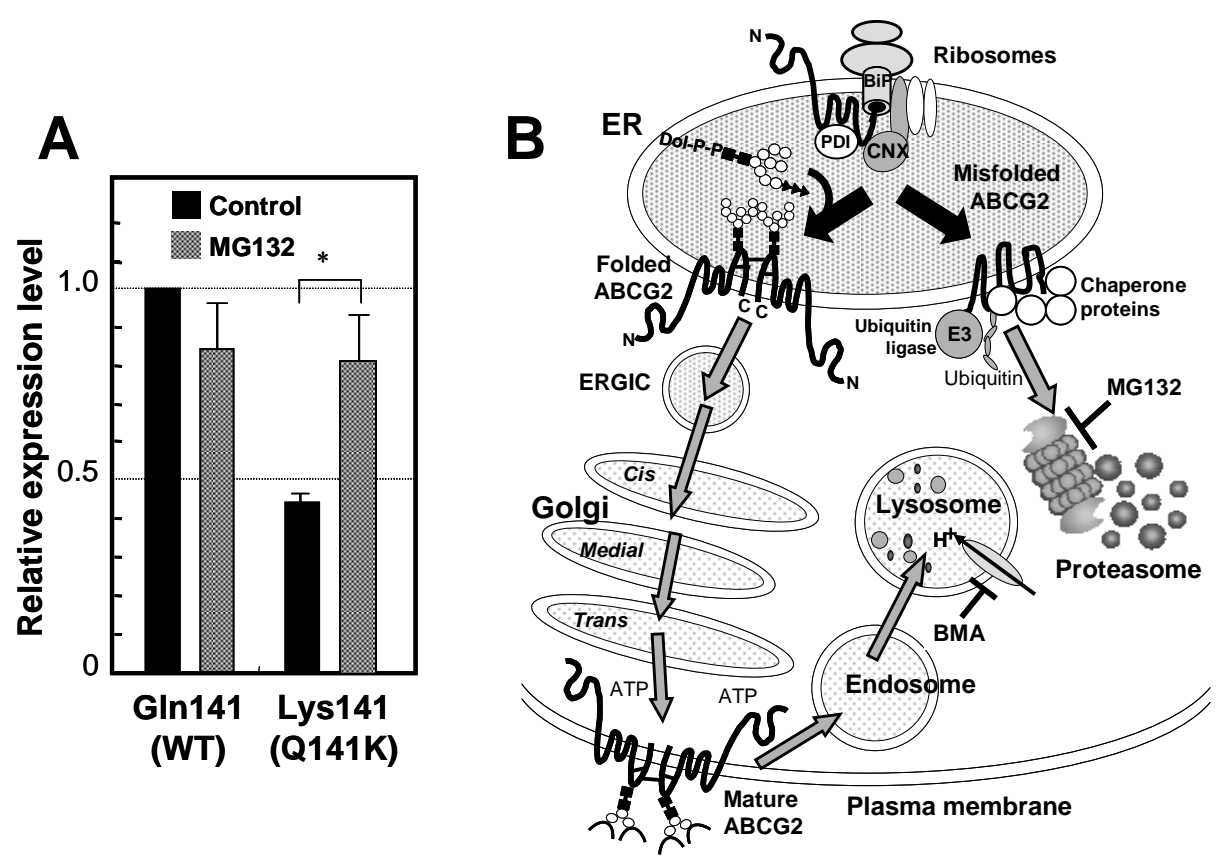

\section{Genetic Polymorphisms in ABCG2 Gene}

The de novo synthesized ABCG2 protein undergoes the formation of inter- and intramolecular disulfide bonds in the lumen of endoplasmic reticulum (ER) by the action of protein disulfide 
isomerase and FAD-bound ER oxidoreductin 1 [34,35] (Figure 5B). The ABCG2 protein is then $N$-glycosylated at Asn596. $N$-linked glycans are added en block to proteins as "core oligosaccharides" $\left(\mathrm{Glc}_{3} \mathrm{Man}_{9} \mathrm{GlcNAc}_{2}\right)$. Calnexin $(\mathrm{CNX})$ is located near the translocon and can interact with nascent peptide chains of $N$-linked glycosylated proteins. After $N$-glycosylation, ABCG2 protein is transferred to the Golgi for further processing. The correctly processed ABCG2 protein is finally destined to the plasma membrane and then degraded by the endosome-lysosome pathway after remaining in the plasma membrane domain for a certain period. In contrast, the misfolded ABCG2 protein undergoes ubiquitination-mediated proteasomal degradation. Bafilomycin $\mathrm{A}_{1}$ (BMA) and MG132 inhibit lysosomal and proteasomal degradation, respectively.

Sequencing of the ABCG2 gene from human samples has revealed over 80 different, naturally occurring sequence variations. [36-46]. Amongst them, SNP 421C $>$ A polymorphism located in exon 5 leads to the replacement of the glutamine residue with a positively charged lysine residue. This polymorphism affects the ATP-binding domain, between the Walker A motif (amino acid residues 83-89) and the signature region (amino acid residues 186-189). This SNP variant has also been detected in all ethnic groups tested: the allele frequency ranged between $0 \%$ and $35 \%$, (North-Saharan Africans, sub-Saharan Africans, and African-American subjects with low; and Japanese and Chinese populations with high allele frequencies) $[36,39,40,43,44]$ (Figure 6).

Figure 6. The allele frequencies of $421 \mathrm{C}$ (WT) and 421A (Q141K) among different ethnic populations. Data are calculated from Ishikawa et al. [36].

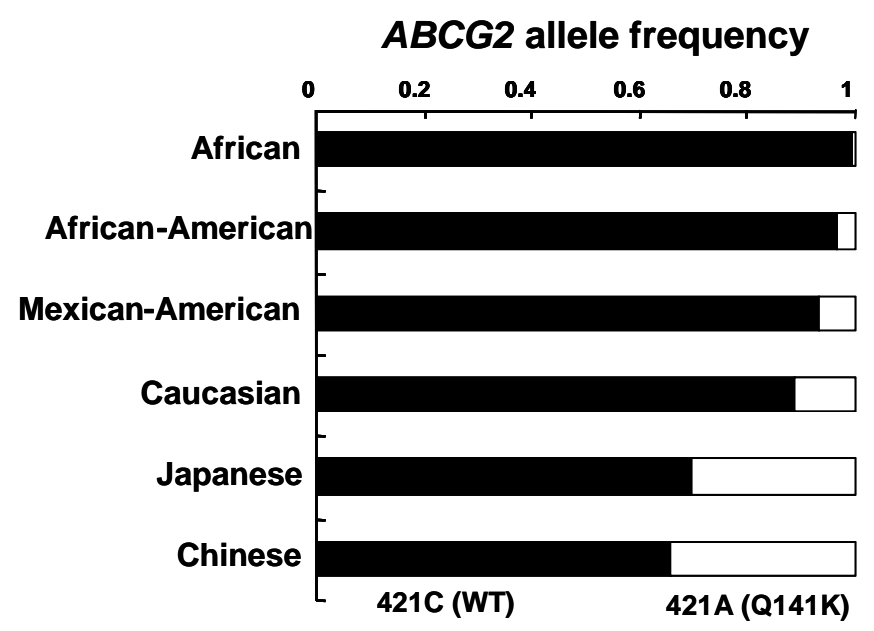

An investigation of the expression level of ABCG2 in 99 Japanese placenta samples revealed that individuals homozygous for the Q141K variant showed significantly lower expression levels of this transporter protein, while the heterozygous samples displayed intermediate expression levels [44]. Based on those observations, it is assumed that the protein stability of the Q $141 \mathrm{~K}$ variant is significantly reduced without showing significant changes in its mRNA levels. Evidence has been provided to show that the Q141K variant of ABCG2 is degraded via ubiquitin-mediated proteasomal degradation [31-35]. The level of the Q141K variant protein could be recovered when proteosomal degradation was inhibited by MG132 in vitro (Figure 5A). The Q141K mutation does not interfere with the nucleotide-binding domain/intracellular loop interactions but greatly affect the protein-protein 
interactions necessary for the dimerization of ABCG2. Two amino acid residues, i.e., Lys-473 (K473) and Phe-142 (F142), were found to play a pivotal role in dimerization of ABCG2 protein [47].

In addition to the Q141K variant, a minor SNP in exon 4, 376C $>\mathrm{T}$, substituting a stop codon for Gln126, was found in the Japanese population with an allele frequency of $2.4 \%$ [37]. It has been postulated that the $376 \mathrm{C}>\mathrm{T}$ SNP may have a high impact, since active ABCG2 protein will not be synthesized from the variant allele. The variant Q126stop (376C $>\mathrm{T})$ was consistently observed in certain Japanese cohorts; however, it was absent in Caucasian and African-American groups [39,41,44]. Matsuo et al. [4] reported that the genotype combinations of Q126stop and Q141K are clinically important biomarkers to predict the possible risk of gout in the Japanese population.

In the US, approximately three million individuals are suffering from often insufficiently treated gout. Woodward et al. [30] performed a population-based study with 14,783 individuals to examine SNP 421C $>$ A (rs2231142) as the causal variant. Highly significant associations were found between uric acid levels in blood and the incidence of gout (adjusted odds ratio 1.68). Their data suggest that at least $10 \%$ of all gout cases in Caucasians are attributable to SNP 421C $>$ A (Q141K).

\section{Rapid Genotyping to Assess Gout Risk}

Genetic diagnostics is a growing field that is gradually becoming more user-friendly with the introduction of portable devices and faster nucleic acid detection. Figure 7 shows the detection of SNP $421 \mathrm{C}>\mathrm{A}$ in the ABCG2 gene by the SmartAmp method. This method was developed based on the principal concept that DNA amplification itself is the signal for detection of a genetic mutation or SNP. Differing from the widely-used PCR, the SmartAmp method consists of both isothermal DNA amplification and SNP-discriminating reactions [48].

In the SmartAmp method, the entire DNA amplification process requires five primers: turnback primer (TP), boost primer (BP), forward primer (FP), and two outer primers (OP1 and OP2) (Table 1). Primers are selected based on the SmartAmp primer algorithm by using the optimal melting temperature and product size range. The genomic sequence between the annealing sites of the TP and FP primers is the target region that will be amplified by the reaction (Figure 7).

Table 1. Primer sets to detect WT and SNP alleles in the human ABCG2 gene.

\begin{tabular}{ll}
\hline & \multicolumn{1}{c}{ WT (421C)-detection Primer Set } \\
\hline Primer & Sequence $\left(\mathbf{5}^{\prime} \rightarrow \mathbf{3}^{\prime}\right)$ \\
\hline TP & GTAAGTTTCCTTAAGGATGATGTTGTG \\
FP & ACCTTCTGTACCCTCAGAAGGTGCCGAAGAGCTGCTGAGAAC \\
BP & ACCGTCAGAGTGCCCAT \\
OP1 & TTATCATTATGTCTCATT \\
OP2 & ATGATTCGTCATAGTTGT \\
\hline \multicolumn{1}{c}{ SNP (421A)-detecting Primer Set } \\
\hline Primer & Sequence (5' $\left.\rightarrow \mathbf{3}^{\prime}\right)$ \\
\hline TP & TTTAAGTTTCTCTTAAGGATGATGTTGTG \\
FP & ACCTTCTGTACCCTCAGAAGGTGCCGAAGAGCTGCTGAGAAC \\
BP & ACCGTCAGAGTGCCCAT \\
OP1 & TTATCATTATGTCTCATT \\
OP2 & ATGATTCGTCATAGTTGT \\
\hline
\end{tabular}


Figure 7. Rapid genetic testing to assess gout risk by the SmartAmp method. (A) Schematic illustration of the human ABCG2 gene located on chromosome $4 \mathrm{q} 22$. The SNP $421 C>A$ resides in exon 5. (B) Detection of SNP $421 C>A$ in the human ABCG2 gene by the SmartAmp method. Three panels depict the time-courses of the SmartAmp assay reactions with ABCG2 allele-specific primers carrying WT (421C) or SNP (421A) alleles; namely, $\mathrm{C} / \mathrm{C}$ homozygote, $\mathrm{C} / \mathrm{A}$ heterozygote, and A/A homozygote. After genomic DNA in peripheral blood samples $(5 \mu \mathrm{L})$ was denatured at $98{ }^{\circ} \mathrm{C}$ for $3 \mathrm{~min}$, the genotyping reactions were allowed to proceed isothermally at $60{ }^{\circ} \mathrm{C}$ for $60 \mathrm{~min}$ in a Mx3000P PCR system (Agilent Technologies, Santa Clara, CA, USA) [48]. DNP amplification was continuously monitored by detecting the fluorescence of DNA-intercalated SYBR Green I dye in the reaction mixture.

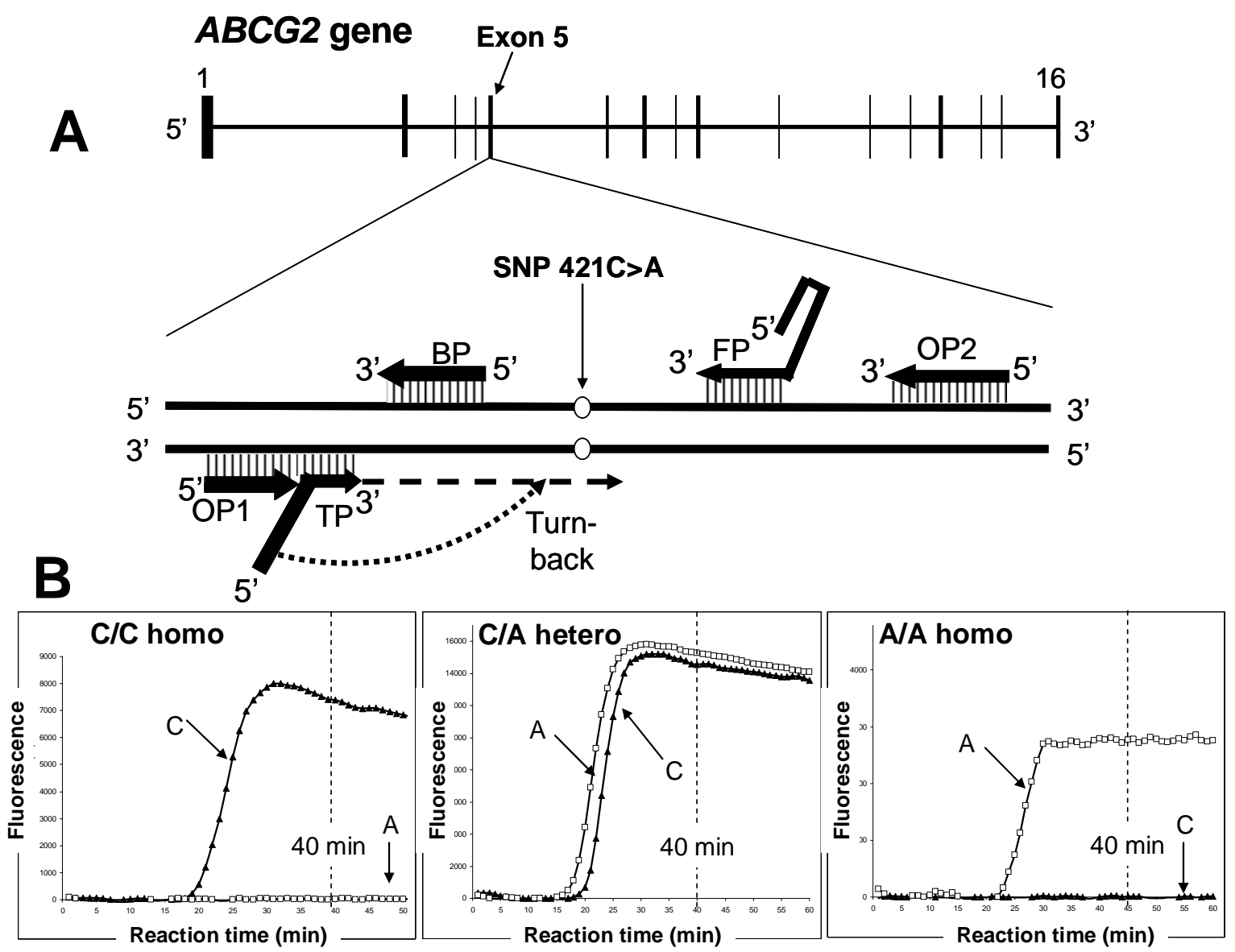

DNA polymerase reaction proceeds from the 3'-end of TP primer (see Figure 7), and the turn-back region (underline) of TP primer recognizes the nucleotide ( $\mathrm{C}$ or $\mathrm{A}$ ) corresponding to the position 421 in the newly synthesized DNA strand. The C-or-A recognizing nucleotide ( $\mathrm{G}$ or $\mathrm{T}$ ) is marked by a square in the sequence of each TP primer. The molar ratio of primers in the genotyping reaction mixture was TP:FP:BP:OP1:OP2 = 8:8:4:1:1.

In the SmartAmp method, clinical samples are processed by using the enzyme Aac polymerase. This enzyme is highly resistant to cellular contaminants and hence works directly on blood samples, following a simple heat treatment $\left(98^{\circ} \mathrm{C}, 3 \mathrm{~min}\right)$ to degrade RNA and denature proteins [48]. This is a great advantage of the SmartAmp method over the commonly used PCR-based techniques with 
Taq DNA polymerase, which is easily inhibited by impurities. The application of SmartAmp for practical diagnostics should be evaluated according to the principle of amplification versus non-amplification with respect to threshold values. The amount of DNA-intercalating SYBR Green I dye accumulated during the reaction is monitored, and thereby SNP typing can be determined by referring to the intensity of the non-amplification fluorescence.

Recently Matsuo et al. examined their hypothesis of whether common dysfunction of ABCG2 causes early-onset gout [49]. They genotyped a total of 705 Japanese male gout patients with onset age data as well as 1,887 male controls. ABCG2 functions were estimated based on genotype combinations $(421 \mathrm{C}>\mathrm{A}$ and $376 \mathrm{C}>\mathrm{T})$. They found that the onset age was 6.5 years earlier with severe ABCG2 dysfunction than with normal ABCG2 function $\left(p=6.14 \times 10^{-3}\right)$. Patients with mild to severe ABCG2 dysfunction accounted for $88.2 \%$ of early-onset cases (twenties or younger). Severe ABCG2 dysfunction particularly increased the risk of early-onset gout (odds ratio 22.2, $p=4.66 \times 10^{-6}$ ). Based on those findings, Matsuo et al. conclude that common dysfunction of ABCG2 is a major cause of early-onset gout [49]. Thus, genotyping of the ABCG2 gene would serve to improve prevention and early therapeutic intervention for high-risk individuals.

\section{Conclusions}

Nowadays, pharmacogenomics is widely used in predicting drug efficacy and drug-induced adverse reactions [50]. This knowledge on the effects of genetic polymorphisms is applicable in drug discovery and development as well as in the clinical use of drugs. Increases in efficacy and safety by the individualization of medical treatment may have benefits in financial terms, if information is presented to show that personalized medicine will be cost-effective in healthcare systems. In fact, several genetic polymorphisms in drug metabolizing enzyme genes (e.g., CYP2C9, CYP2C19, CYP2D6, TPMT, VKORC1) and transporter genes (e.g., SLCO1B1 and ABCG2) are on the list of genetic testing in personalized medicine. As described in this article, the SNPs of $421 \mathrm{C}>\mathrm{A}$ and $376 \mathrm{C}>\mathrm{T}$ in the human $A B C G 2$ gene are recognized as clinical biomarkers to assess hyperuricemia and gout.

The rapid growth of personalized medicine is being supported by emerging new technologies together with accumulating knowledge of pharmacogenomics. Basic technologies of molecular diagnostics play a role in expanding pharmacogenomic information, particularly with respect to SNP genotyping. Diagnosis is thus integrated with therapy for selecting treatments as well for monitoring results. Cost-effective methods should be developed for genotyping, however, and it would be desirable to include this information in the patient's record as guidance for physicians to individualize the treatment. The accurate measurement of allele frequency variations among population groups with different sensitivities to diseases and/or different responses to drugs is fundamental to genetic epidemiology. Development of personalized medicine, including point-of-care technology, requires the integration of various segments of biotechnology, clinical medicine, and pharmacology. Multiple players could promise the realization of personalized medicine and personalized healthcare. 


\section{Acknowledgments}

The authors thank Emeritus Hitoshi Endou (Kyorin University School of Medicine, Tokyo, Japan) for his valuable comments and critical reading of this manuscript. This study was supported by a Japan Science and Technology Agency (JST) research project named "Development of the World's Fastest SNP Detection System" (to TI) and Research Grant for RIKEN Center for Life Science Technologies from the Ministry of Education, Culture, Sports, Science and Technology.

\section{Conflicts of Interest}

The authors declare no conflict of interest.

\section{References}

1. Giacomini, K.M.; Huang, S.M.; Tweedie, D.J.; Benet, L.Z.; Brouwer, K.L.; Chu, X.; Dahlin, A.; Evers, R.; Fischer, V.; Hillgren, K.M.; et al. Membrane transporters in drug development: Report from the FDA critical path initiative-sponsored workshop. Nat. Rev. Drug Discov. 2010, 9, 215-236.

2. Ishikawa, T. Multidrug resistance: Genomics of ABC transporters. Nat. Encycl. Hum. Genome 2003, 4, 154-160.

3. Doyle, L.A.; Yang, W.; Abruzzo, L.V.; Krogmann, T.; Gao, Y.; Rishi, A.K.; Ross, D.D. A multidrug resistance transporter from human MCF-7 breast cancer cells. Proc. Natl. Acad. Sci. USA 1998, 95, 15665-15670.

4. Matsuo, H.; Takada, T.; Ichida, K.; Nakamura, T.; Nakayama, A.; Ikebuchi, Y.; Ito, K.; Kusanagi, Y.; Chiba, T.; Tadokoro, S.; et al. Common defects of ABCG2, a high-capacity urate exporter, cause gout. A function-based genetic analysis in a Japanese population. Sci. Transl. Med. 2009, 1, 5 ra11.

5. Woodward, O.; Köttgen, A.; Coresh, J.; Boerwinkle, E.; Guggino, W.B.; Köttgen, M. Identification of a urate transporter, $\mathrm{ABCG}$, with a common functional polymorphism causing gout. Proc. Natl. Acad. Sci. USA 2009, 106, 10338-10342.

6. Richette, P.; Bardin, T. Purine-rich foods: An innocent bystander of gout attacks? Ann. Rheum. Dis. 2012, 71, 1435-1436.

7. Choi, H.K.; Ford, E.S. Prevalence of the metabolic syndrome in individuals with hyperuricemia. Am. J. Med. 2007, 120, 442-447.

8. Choi, H.K.; Mount, D.B.; Reginato, A.M.; American College of Physicians; American Physiological Society. Pathogenesis of gout. Ann. Intern. Med. 2005, 143, 499-516.

9. Iribarren, C.; Folsom, A.R.; Eckfeldt, J.H.; McGovern, P.G.; Nieto, F.J. Correlates of uric acid and its association with asymptomatic carotid atherosclerosis: The ARIC study atherosclerosis risk in communities. Ann. Epidemiol. 1996, 6, 331-340.

10. Anzai, N.; Kanai, Y.; Endou, H. New insights into renal transport of urate. Curr. Opin. Rheumatol. 2007, 19, 151-157.

11. Enomoto, A.; Endou, H. Roles of organic anion transporters (OATs) and a urate transporter (URAT1) in the pathophysiology of human disease. Clin. Exp. Nephrol. 2005, 9, 195-205. 
12. Enomoto, A.; Kimura, H.; Chairoungdua, A.; Shigeta, Y.; Jutabha, P.; Cha, S.H.; Hosoyamada, M.; Takeda, M.; Sekine, T.; Igarashi, T.; et al. Molecular identification of a renal urate anion exchanger that regulates blood urate levels. Nature 2002, 417, 447-452

13. Li, S.; Sanna, S.; Maschio, A.; Busonero, F.; Usala, G.; Mulas, A.; Lai, S.; Dei, M.; Orrù, M.; Albai, G.; et al. The GLUT9 Gene is associated with serum uric acid levels in Sardinia and Chianti Cohorts. PLoS Genet. 2007, 3, e194.

14. Wallace, C.; Newhouse, S.J.; Braund, P.; Zhang, F.; Tobin, M.; Falchi, M.; Ahmadi, K.; Dobson, R.J.; Marçano, A.C.; Hajat, C.; et al. Genome-wide association study identifies genes for biomarkers of cardiovascular disease: Serum urate and dyslipidemia. Am. J. Hum. Genet. 2008, 82, 139-149.

15. Döring, A.; Gieger, C.; Mehta, D.; Gohlke, H.; Prokisch, H.; Coassin, S.; Fischer, G.; Henke, K.; Klopp, N.; Kronenberg, F.; et al. SLC2A9 influences uric acid concentrations with pronounced sex-specific effects. Nat. Genet. 2008, 40, 430-436.

16. Vitart, V.; Rudan, I.; Hayward, C.; Gray, N.K.; Floyd, J.; Palmer, C.N.; Knott, S.A.; Kolcic, I.; Polasek, O.; Graessler, J.; et al. SLC2A9 is a newly identified urate transporter influencing serum urate concentration, urate excretion and gout. Nat. Genet. 2008, 40, 437-442.

17. Matsuo, H.; Chiba, T.; Nagamori, S.; Nakayama, A.; Domoto, H.; Phetdee, K.; Wiriyasermkul, P.; Kikuchi, Y.; Oda, T.; Nishiyama, J.; et al. Mutations in glucose transporter 9 gene SLC2A9 cause renal hypouricemia. Am. J. Hum. Genet. 2008, 83, 744-751.

18. Rizwan, A.N.; Burckhardt, G. Organic anion transporters of the SLC22 family: Biopharmaceutical, physiological, and pathological roles. Pharm. Res. 2007, 24, 450-470.

19. Van Aubel, R.A.; Smeets, P.H.; van den Heuvel, J.J.; Russel, F.G. Human organic anion transporter MRP4 (ABCC4) is an efflux pump for the purine end metabolite urate with multiple allosteric substrate binding sites. Am. J. Physiol. Renal Physiol. 2005, 288, F327-F333.

20. Huls, M.; Brown, C.D.; Windass, A.S.; Sayer, R.; van den Heuvel, J.J.; Heemskerk, S.; Russel, F.G.; Masereeuw, R. The breast cancer resistance protein transporter ABCG2 is expressed in the human kidney proximal tubule apical membrane. Kidney Int. 2008, 73, 220-225.

21. Krishnamurthy, P.; Schuetz, J.D. Role of ABCG2/BCRP in biology and medicine. Annu. Rev. Pharmacol. Toxicol. 2006, 46, 381-410.

22. Choi, H. Epidemiology of crystal arthropathy. Rheum. Dis. Clin. North Am. 2006, 32, 255-273.

23. Saag, K.G.; Choi, H. Epidemiology, risk factors, and lifestyle modifications for gout. Arthritis Res. Ther. 2006, 8, S2.

24. Becker, M.A.; Schumacher, H.R., Jr.; Wortmann, R.L.; MacDonald, P.A.; Eustace, D.; Palo, W.A.; Streit, J.; Joseph-Ridge, N. Febuxostat compared with allopurinol in patients with hyperuricemia and gout. N. Engl. J. Med. 2005, 353, 2450-2461.

25. Kaneko, K.; Kobayashi, R.; Yasuda, M.; Izumi, Y.; Yamanobe, T.; Shimizu, T. Comparison of matrix proteins in different types of urinary stone by proteomic analysis using liquid chromatography-tandem mass spectrometry. Int. J. Urol. 2012, 19, 765-772.

26. Hamada, T.; Ichida, K.; Hosoyamada, M.; Mizuta, E.; Yanagihara, K.; Sonoyama, K.; Sugihara, S.; Igawa, O.; Hosoya, T.; Ohtahara, A.; et al. Uricosuric action of losartan via the inhibition of urate transporter 1 (URAT 1) in hypertensive patients. Am. J. Hypertens. 2008, 21, 1157-1162. 
27. Deghan, A.; Köttgen, A.; Yang, Q.; Hwang, S.J.; Kao, W.L.; Rivadeneira, F.; Boerwinkle, E.; Levy, D.; Hofman, A.; Astor, B.C.; et al. Association of three genetic loci with uric acid concentration and risk of gout: A genome-wide association study. Lancet 2008, 372, 1953-1961.

28. Kolz, M.; Johnson, T.; Sanna, S.; Teumer, A.; Vitart, V.; Perola, M.; Mangino, M.; Albrecht, E.; Wallace, C.; Farrall, M.; et al. Meta-analysis of 28,141 individuals identifies common variants within five new loci that influence uric acid concentrations. PLoS Genet. 2009, 5, e1000504.

29. Stark, K.; Reinhard, W.; Grassi, M.; Erdmann, J.; Schunkert, H.; Illig, T.; Hengstenberg, C. Common polymorphisms influencing serum uric acid levels contribute to susceptibility to gout, but not to coronary artery disease. PLoS One 2009, 4, e7729.

30. Zhang, L.; Spencer, K.L.; Voruganti, V.S.; Jorgensen, N.W.; Fornage, M.; Best, L.G.; Brown-Gentry, K.D.; Cole, S.A.; Crawford, D.C.; Deelman, E.; et al. Association of functional polymorphism rs2231142 (Q141K) in the ABCG2 gene with serum uric acid and gout in 4 US populations: The PAGE study. Am. J. Epidemiol. 2013, 177, 923-932.

31. Tamura, A.; Wakabayashi, K.; Onishi, Y.; Takeda, M.; Ikegami, Y.; Sawada, S.; Tsuji, M.; Matsuda, Y.; Ishikawa, T. Re-evaluation and functional classification of nonsynonymous single nucleotide polymorphisms of human ABC transporter ABCG2. Cancer Sci. 2007, 98, 231-239.

32. Nakagawa, H.; Tamura, A.; Wakabayashi, K.; Hoshijima, K.; Komada, M.; Yoshida, T.; Kometani, S.; Matsubara, T.; Mikuriya, K.; Ishikawa, T. Ubiquitin-mediated proteasomal degradation of non-synonymous SNP variants of human ABC transporter ABCG2. Biochem. J. 2008, 411, 623-631.

33. Furukawa, T.; Wakabayashi, K.; Tamura, A.; Nakagawa, H.; Morishima, Y.; Osawa, Y.; Ishikawa, T. Major SNP (Q141K) variant of human ABC transporter ABCG2 undergoes lysosomal and proteosomal degradations. Pharm. Res. 2009, 26, 469-479.

34. Wakabayashi-Nakao, K.; Tamura, A.; Furukawa, T.; Nakagawa, H.; Ishikawa, T. Quality control of human ABCG2 protein in the endoplasmeic reticulm: Ubiquitination and proteasomal degradation. Adv. Drug Deliv. Rev. 2009, 61, 66-72.

35. Nakagawa, H.; Toyoda, Y.; Wakabayashi-Nakao, K.; Tamaki, H.; Osumi, M.; Ishikawa, T. Ubiquitin-mediated proteasomal degradation of $\mathrm{ABC}$ transporters: A new aspect of genetic polymorphisms and clinical impacts. J. Parm. Sci. 2011, 100, 3602-3619.

36. Ishikawa, T.; Tamura, A.; Saito, H.; Wakabayashi, K.; Nakagawa, H. Pharmacogenomics of the human $\mathrm{ABC}$ transporter ABCG2: From functional evaluation to drug molecular design. Naturwissenschaften 2005, 92, 451-463.

37. Honjo, Y.; Morisaki, K.; Huff, L.M.; Robey, R.W.; Hung, J.; Dean, M.; Bates, S.E. Single-nucleotide polymorphism (SNP) analysis in the ABC half-transporter ABCG2 (MXR/BCRP/ABCP1). Cancer Biol. Ther. 2002, 1, 696-702.

38. Iida, A.; Saito, S.; Sekine, A.; Mishima, C.; Kitamura, Y.; Kondo, K.; Harigae, S.; Osawa, S.; Nakamura, Y. Catalog of 605 single-nucleotide polymorphisms (SNPs) among 13 genes encoding human ATP-binding cassette transporters: ABCA4, ABCA7, ABCA8, ABCD1, ABCD3, ABCD4, ABCE1, ABCF1, ABCG1, ABCG2, ABCG4, ABCG5, and ABCG8. J. Hum. Genet. 2002, 47, 285-310. 
39. Imai, Y.; Nakane, M.; Kage, K.; Tsukahara, S.; Ishikawa, E.; Tsuruo, T.; Miki, Y.; Sugimoto, Y. C421A polymorphism in the human breast cancer resistance protein gene is associated with low expression of Q141K protein and low-level drug resistance. Mol. Cancer Ther. 2002, 1, 611-616.

40. Zamber, C.P.; Lamba, J.K.; Yasuda, K.; Farnum, J.; Thummel, K.; Schuetz, J.D.; Schuetz, E.G. Natural allelic variants of breast cancer resistance protein (BCRP) and their relationship to BCRP expression in human intestine. Pharmacogenetics 2003, 13, 19-28.

41. Itoda, M.; Saito, Y.; Shirao, K.; Minami, H.; Ohtsu, A.; Yoshida, T.; Saijo, N.; Suzuki, H.; Sugiyama, Y.; Ozawa, S.; et al. Eight novel single nucleotide polymorphisms in ABCG2/BCRP in Japanese cancer patients administered Irinotecan. Drug Metab. Pharmacokin. 2003, 18, 212-217.

42. Bäckström, G.; Taipalensuu, J.; Melhus, H.; Brandstrom, H.; Svensson, A.C.; Artursson, P.; Kindmark, A. Genetic variation in the ATP-binding cassette transporter gene ABCG2 (BCRP) in a Swedish population. Eur. J. Pharm. Sci. 2003, 18, 359-364.

43. De Jong, F.A.; Marsh, S.; Mathijssen, R.H.; King, C.; Verweij, J.; Sparreboom, A.; McLeod, H.L. ABCG2 pharmacogenetics: Ethnic differences in allele frequency and assessment of influence on irinotecan disposition. Clin. Cancer Res. 2004, 10, 5889-5894.

44. Kobayashi, D.; Ieiri, I.; Hirota, T.; Takane, H.; Maegawa, S.; Kigawa, J.; Suzuki, H.; Nanba, E.; Oshimura, M.; Terakawa, N.; et al. Functional assessment of ABCG2 (BCRP) gene polymorphisms to protein expression in human placenta. Drug Metab. Dispos. 2005, 33, 94-101.

45. Bosch, T.M.; Kjellberg, L.M.; Bouwers, A.; Koeleman, B.P.C.; Schellens, J.H.M.; Beijnen, J.H.; Smits, P.H.M.; Meijerman, I. Detection of single nucleotide polymorphisms in the ABCG2 gene in a Dutch population. Am. J. Pharmacogenomics 2005, 5, 123-131.

46. Basseville, A.; Bates, S.E.; Figg, W.D.; Sparreboom, A. BCRP (ABCG2). In Pharmacogenomics of Human Drug Transporters: Clinical Impacts, 1st ed.; Ishikawa, T., Kim, R.B., König, J., Eds.; John Wiley \& Sons, Inc.: Hoboken, NJ, USA, 2013; pp. 311-343.

47. Woodward, O.M.; Tukaye, D.N.; Cui, J.; Greenwell, P.; Constantoulakis, L.M.; Parker, B.S.; Rao, A.; Köttgen, M.; Maloney, P.C.; Guggino, W.B. Gout-causing Q141K mutation in ABCG2 leads to instability of the nucleotide-binding domain and can be corrected with small molecules. Proc. Natl. Acad. Sci. USA 2013, 110, 5223-5228.

48. Ishikawa, T.; Hayashizaki, Y. Clinical SNP detection by the SmartAmp method. Methods Mol. Biol. 2013, 1015, 55-69.

49. Matsuo, H.; Ichida, K.; Takada, T.; Nakayama, A.; Nakashima, H.; Nakamura, T.; Kawamura, Y.; Takada, Y.; Yamamoto, K.; Inoue, H.; et al. Common dysfunctional variants in ABCG2 are a major cause of early-onset gout. Sci. Rep. 2013, 3, 2014.

50. Ishikawa, T.; Ware, J. Future Perspectives. In Pharmacogenomics of Human Drug Transporters: Clinical Impacts, 1st ed.; Ishikawa, T., Kim, R.B., König, J., Eds.; John Wiley \& Sons, Inc.: Hoboken, NJ, USA, 2013; pp. 401-416.

(C) 2013 by the authors; licensee MDPI, Basel, Switzerland. This article is an open access article distributed under the terms and conditions of the Creative Commons Attribution license (http://creativecommons.org/licenses/by/3.0/). 